\title{
FUNÇÃO SOCIAL DA TERRA - PRINCÍPIO FUNDAMENTAL PARA CONSERVAÇÃO DA VITALIDADE E DIVERSIDADE DO PLANETA
}

\author{
LILIAN BESSA OLINTO
}




\section{FUNÇÃO SOCIAL DA TERRA - PRINCÍPIO FUNDAMENTAL PARA CONSERVAÇ̃̃O DA VITALIDADE E DIVERSIDADE DO PLANETA}

\section{LILIAN BESSAOLINTO}

\section{RESUMO}

Este artigo traz um estudo sobre a função social da terra, entendendo-a como um princípio fundamental que garante e orienta a conversação da vitalidade e diversidade do planeta, porque está voltado para o homem, e mais, porque a terra não pode ser considerada uma mercadoria, mas meio de produção ou de utilidade social. Para melhor compreensão do tema o conhecimento sobre direito de propriedade e o conceito de função social da terra são imprescindíveis, e a leitura sistemática do ordenamento jurídico e a situação topográfica deste princípio na Constituição Federal demonstram igualmente sua importância. A terra deve atender as necessidades da sociedade, tendo o homem como seu parceiro, fazendo-a produzir para cumprir a finalidade social, porém de uma maneira que conserve um ambiente ecologicamente estável para as gerações futuras. A função social da terra estará cumprida quando além do maior número de pessoas tiver acesso a ela para viver e trabalhar, produzindo alimentos para uma parcela considerável da população mundial, mas essencialmente conservando os recursos naturais e observando o bem estar de todos, garantindo um desenvolvimento sustentável no campo, ressaltando a importância de uma reforma agrária que valorize as pessoas e não uma reforma de mercado, promovida por instituições internacionais que se preocupam somente com o lucro, em produzir em larga escala.

\footnotetext{
${ }^{1}$ Especialista em Política e Estratégias Nacionais pela ADESG, Especialista em Docência Universitária pela UCB, Especialista em Direito Civil e Processo Civil pela UNITINS, Pós-graduanda do Curso de Especialização em Direito Constitucional da UNITINS, Texto orientado pela professora Ângela Issa Haonat
} 


\section{Palavras-chave:}

função social da terra, direito de propriedade, conversação do planeta.

\section{RESUMEN}

Este artículo trae un estudio sobre la función social de la tierra, entendiéndola como un principio que garantiza y orienta la conservación de la vitalidad y diversidad del planeta, porque está puesto para el hombre, y además, porque la tierra no puede ser considerada una mercancía, sino el medio de producción o de utilidad social. Para mejor comprensión del tema, el conocimiento sobre derecho de propiedad y el concepto de función social de la tierra son imprescindibles, y la lectura sistemática del ordenamiento jurídico y la posición topográfica de este principio en la Constitución Federal demuestran igualmente su importancia. La tierra debe atender a las necesidades de la sociedad, teniendo el hombre como su compañero, haciéndola producir para cumplir el fin social, todavía de un modo que conserve un ambiente ecológicamente estable para las generaciones futuras. La función social de la tierra estará cumplida cuando un mayor número de personas tenga acceso a ella para vivir e trabajar, produciendo alimentos para una parte considerable de la población mundial, pero esencialmente conservando los recursos naturales y observando el bienestar de todos, garantizando un desarrollo sustentable en el campo, resaltando la importancia de una reforma agraria que valore las personas y no una reforma de mercado, promocionada por instituciones internacionales que se preocupan sólo con la ganancia, en producir en gran escala.

\section{Palabras-clave:}

función social de la tierra, derecho de propiedad, conservación del planeta. 


\section{INTRODUÇÃO}

A relevância da discussão da função social da terra está na busca de soluções das questões que estão voltadas à finalidade de garantir a sobrevivência humana, visto a terra ser um bem essencial à vida. 0 princípio da função social deve ser entendido em sua acepção ampla, ou seja, não é apenas a função social da propriedade ou do imóvel rural que deve ser cumprida e, sim, da terra como um todo. Seria inadmissível pensar em um direito designado a atender somente proprietários de terra ou grandes empresários que lucram com a larga produção de bens de consumo, destarte a função social da terra está inexoravelmente impregnada com a dignidade do ser humano, e mais, com a conservação do próprio planeta.

A idéia de função social da terra deve ser estudada em paralelo com o desenvolvimento do direito de propriedade ao longo da história das civilizações, visto que a questão da terra está imbricada com a noção dominialidade, para isso apresentamos brevemente um histórico sobre o direito de propriedade através de todos os períodos históricos e também sua importância para algumas importantes civilizações e filósofos do Iluminismo. Na seqüência, para valorizar o tema fizemos uma abordagem nas várias legislações e Constituições brasileiras, para desaguar nas atuais mudanças com o Estatuto da Cidade e o novo Código Civil.

Como tudo numa ciência social é difícil de conceituar, houve uma tentativa de definir a função social da terra sob o aspecto doutrinário, transcrevendo conceitos de grandes mestres que estudaram o assunto.

Os fundamentos da função social da terra também foram abordados, fazendo um inter-relacionamento com o direito de propriedade segundo a visão individualista, socialista e tomista.

0 tema foi analisado através de uma leitura sistemática do ordenamento jurídico brasileiro, destacando três fatores: econômico, ambiental e humano. Para concluir que a função social da terra estará 
cumprida quando além do maior número de pessoas tiver acesso a terra para viver e trabalhar, produzindo alimentos para um quantitativo maior de pessoas, conservando os recursos naturais, garantindo um desenvolvimento sustentável no campo, ressaltando a importância de uma reforma agrária que valorize as pessoas e não uma reforma de mercado, promovida por instituições internacionais que se preocupam somente com o lucro, em produzir em larga escala.

\section{BREVE HISTÓRICO SOBRE O DIREITO DE PROPRIEDA- DE}

O histórico a ser apresentado tem como base bibliográfica a obra de Roberto Wagner Marquesi.

Iniciamos com o Período Pré-Histórico (opiniões dedutivas do autor mencionado) - é um período de incógnita. A aceitação da teoria da apropriação exclusiva sobre as coisas é pacífica, mas com a noção de propriedade o mesmo não ocorre. A posse restringia-se às coisas móveis, visto a abundância de terra e o pequeno contingente populacional, associado aos hábitos nômades, fatores que levam a crer no desinteresse no monopólio do espaço físico. Entretanto, alguns admitem a posse imobiliária comunitária em toda a proto-história (homem sedentário 10.000 a.C.).

Quanto às Primeiras Civilizações (5.000 a.C.) - "Os sumérios e os semitas, que viveram na Mesopotâmia entre os anos 5.000 a 605 a.C. não foram nômades e fixaram-se ao longo dos rios e vales montanhosos" (MARQUESI:2001, p. 61). 0 desenvolvimento de técnicas agrícolas faz surgir o trabalho comunitário e o apossamento com uma visão do solo como propriedade do deus local. As vantagens decorrentes da posse progridem para um interesse individual, fazendo surgir as primeiras noções de dominialidade.

No que se refere ao Código de Hamurabi (1792 a.C.), Alcir Gursen Miranda, citado por Benedito Ferreira Marques, afirma que "o Código de Hamurabi, do povo babilônico, pode ser considerado o primeiro 
Código Agrário da Humanidade", dos 280 artigos, 65 teriam conteúdo agrário. Previu o respeito à propriedade, com sanções para a violação.

Para os Egípcios a aquisição da posse parece ter sido por ocupação, havia uma submissão da massa da população, às classes poderosas, obrigando aqueles a cultivarem o vale do Nilo, em seu favor, tornando-os escravos.

Os Gregos concebiam um sistema com três tipos de propriedade, sob o ângulo da exploração: coletiva, explorada por trabalhadores que dividiam a colheita, entregando, depois, a terra para terceiros; a individual, garantia a posse plena, sendo-lhe lícito destiná-la à alienação ou ao testamento; e, a familiar era transmissível por herança. Ressalte-se que Aristóteles, àquela época, entendia "que aos bens se deveria dar uma destinação social, para o que, a seu pensar, seria necessária a apropriação pessoal" (MARQUES:1996, p. 49).

Império Romano (753 a.C. a 476 d.C.) - Tristão Athayde apud Fachin, diz que "os romanos foram propriamente os criadores do direito da propriedade privada, do direito abstrato, do direito privado". Os romanos traçaram seu conteúdo como: dominium est ius utendi et fruendi et abutendi, quatenus iuris patitur ${ }^{2}$. Em Roma a propriedade, vista como individual, constituía direito absoluto e perpétuo, embora com tamanha amplitude o direito de propriedade possuía limitações em seu exercício, surgindo inclusive, no período pós-clássico a possibilidade de sua perda, quando o proprietário que não cultivasse seu terreno, em favor de quem o cultivou por mais de dois anos.

Na Idade Média (476 d.C. até Revolução Francesa, 1789) o conceito unitário da propriedade se modifica, tornando-se uma expres-

\footnotetext{
${ }^{2} \mathrm{O}$ homem sempre computou no número de seus direitos o de apropriar-se de certos bens. Os jurisconsultos romanos definiram isso numa fórmula célebre, ou seja, a propriedade é o direito de reivindicar e de conservar como seu aquilo que foi legitimamente adquirido, de usar, gozar e dispor dessa coisa à vontade, com exclusão de outrem, nos limites da lei (ius utendi, fruendi et abutendi re sua, exclusis aliis, quatenus iuris ratio patitur - Digestae, 7, 8, 2, par).
} 
são do poder político. Surge uma hierarquização na organização do domínio, sendo que o uso da terra ocorria por concessões. A Igreja, encontrava-se integrando a elite dominante, sendo grande proprietária de terras. Apesar do ambiente totalmente desfavorável, no séc. XII, São Thomás de Aquino, em sua Summa Theológica ${ }^{3}$, impulsiona a idéia de que o homem tinha o direito natural de adquirir bens materiais, mas não podia abstrair o dever do "bem comum" (MARQUES:1996, p. 49).

No iluminismo, marca da transição da Idade Média para a Idade Moderna, surge os pensamentos filosóficos que posteriormente vieram constituir o fundamento das novas organizações sociais, para o tema em estudo interessa Hobbes, Locke e Rousseau:

a) Hobbes (T. H. - 1588/1679) - A propriedade tinha uma função política e econômica, em que o Estado cria as regras para o exercício, sendo que os limites definidos pelo Estado são sempre justos, porque advém da vontade do soberano.

b) Locke (J.L. - 1632/1704) - A propriedade é um direito natural, sendo o homem totalmente livre para exercer este direito, sendo função única do Estado, a sua garantia. Entretanto, apesar da sua retórica liberal, entendia que "a propriedade é crucial, sendo que no estado de natureza, fundamenta-se no trabalho" (VIAL:2001, p. 82).

c) Rousseau (J.J. R. - 1712/1778) - A propriedade, assim como a vida social dos indivíduos é resultante da lei, esta, por princípio, sempre é justa porque é a expressão da vontade geral. Afirma que a propriedade surgiu quando alguém se declarou proprietário de uma terra e os demais, estupidamente, teriam levado isso a sério.

Na Idade Moderna (Revolução Francesa até a primeira Guerra Mundial - 1922) - Com a subida da burguesia ao poder, buscou-se uma legislação rígida, de forma a garantir a hegemonia conseguida.

\footnotetext{
${ }^{3}$ Obra básica de São Tomás de Aquino, um corpo de doutrina que se constitui numa das bases da dogmática do catolicismo e consid erada uma das principais obras filosóficas da escolástica. Foi escrita entre os anos de 1265 a 1273.
} 
Napoleão Bonaparte, com seu Código de Napoleão, resgata a propriedade individual e absoluta, legislação que influenciou vários países, inclusive o Brasil.

Idade Contemporânea (primeira Guerra Mundial até a atualidade) - o liberalismo puro de Locke passa a ser substituído por um pensamento de um Estado Social, que deve garantir direitos mínimos aos cidadãos, mitigando a amplitude dos direito dos detentores dos bens de produção. Fazendo renascer a idéia de função social, esse progresso na visão da propriedade teve uma substancial colaboração da Igreja Católica que com suas Encíclicas Papais, capitaneadas pela "Rerum Novarum 4 ", de Leão XII, de 1891. Todas elas realçaram o "direito natural à propriedade dos bens, mas submetido ao dever de satisfazer à coletividade" (MARQUES:1996, p. 5). Hodiernamente, vige nos países ocidentais a garantia do direito de propriedade vinculado ao cumprimento da função social.

\section{A EVOLUÇÃO DA FUNÇÃO SOCIAL DA TERRA NO BRA- SIL}

No Brasil a questão das terras inicia-se com as sesmarias, que foi uma adaptação à legislação vigente em Portugal, datada de 1375, que visava a correção de distorções no uso da terra lusitana, em razão da falta de alimento, determinando o povoamento das terras abandonadas e o aumento da produção, com caráter de verdadeiro confisco. No Brasil, após ocupação, o sistema foi adotado, porém, o sentido foi diferente, objetivava a ocupação dos imensos vazios, impondo obrigações aos sesmeiros, que incluía cultivar a terra, dando sentido econômico que para alguns já se configurava um embrião da função social.

Constituição de 1824 - o art. 179 firma o trinômio liberdade/ propriedade/segurança, adotando o liberalismo em sua plenitude.

\footnotetext{
${ }^{4}$ É uma encíclica escrita pelo Papa Leão XIII a 15 de Maio de 1891. Era uma carta aberta a todos os bispos, debatendo com as condições das classes trab alhadoras (em latim Rerum Novarum significa "Das Coisas Novas").
} 
Abraça-se o individualismo, ressalvando timidamente o poder expropriatório do Estado, ainda como única exceção. Recomenda-se uma lei regulamentadora da desapropriação, que não fora editada no período monárquico.

1822 a 1850 - "Período das Posses" - período in albis do legislativo com referência à aquisição, uso e posse da terra, estabelecendo o crescimento de ocupações indiscriminadas e desorganizadas, sem qualquer controle de vasto território.

Lei das Terras (Lei n. 601, de 18/09/1850) - baseada no modelo agrário austríaco (VIAL:2003, p. 135), teve significativa importância ao definir o instituto de "terras devolutas" e prever a legitimação da posse, mansa e pacífica, com garantias para quem ocupava a terra até a vigência da referida lei, podendo ensejar uma intenção de valoração da Função Social da Terra, principalmente em seu art. 5ำ que exigia cultura e moradia habitual do posseiro. Pretendendo separar terras públicas e particulares, a lei seria eficaz a possibilitar aos posseiros a titulação de suas áreas. A quantidade de posses a serem levantadas, de terras devolutas para medir e a desvalorização das terras devolutas pela falta de procura, foram fatores que conspiraram para a frustração da efetivação da Lei de Terras.

Constituição de 1891 - conserva a regra da propriedade, mas inicia uma limitação quanto ao domínio do subsolo, cabendo à lei ordinária o disciplinamento, que ocorreu com a emenda ao parágrafo 17, editada em 03/09/1926, porém, somente em relação ao uso das minas e jazidas.

Constituição de 1934 - foi a primeira a enunciar, expressamente, o princípio de que o direito de propriedade não poderá ser exercido contra o interesse social, na forma da lei (art. 113, n. 17), lei esta que não foi concebida. No mesmo texto reconheceu aos possuidores rurais o direito de usucapir (art. 125), vinculando a posse e o trabalho como elementos suficientes à aquisição da propriedade, vislumbrando a função social. 
Constituição de 1937 - excluiu o interesse social como limitação ao direito de propriedade, prevendo a desapropriação por necessidade ou utilidade pública, mediante indenização, cujo conteúdo, seria regulado por lei, o que não ocorreu. Repetiu, entretanto, a mesma regra anterior para a usucapião pró-labore.

Constituição de 1946 - vincula o direito de propriedade ao interesse coletivo, sem excluir a necessidade e utilidade pública, estabelecendo, ainda, que o uso da propriedade será condicionado ao bem-estar social, dispunha também, no art. 147, que "A lei poderá (...) promover a justa distribuição da propriedade, com igual oportunidade para todos". Leis Específicas n. 3.365 e 4.947/66 tratam de desapropriação.

Emenda Constitucional n. 10, de 09/11/1964, modificou a Constituição de 1946, em seu art. 147, prevendo a desapropriação da propriedade rural, condicionando o uso ao bem-estar social. Também inseriu a competência da União para legislar sobre Direito Agrário, garantindo sua autonomia legislativa, fato que permitiu a edição do Estatuto da Terra em 1964.

Estatuto da Terra - Lei n. 4.504, de 30/11/1964, lei vigente, foi o primeiro dispositivo legal a conceituar a função social da terra e explicitar os seus requisitos.

Constituição vigente, de 05/10/1988 - Recepcionou os princípios da social-democracia dos Estados Europeus, que, sem se afastar totalmente dos cânones do liberalismo, voltam-se para a questão social, o novo texto garante o direito individual da propriedade, mas o vincula ao atendimento de sua função social. Positivando, pela primeira vez, a expressão Função Social da Propriedade, independentemente de ser rural ou urbana, mantém o usucapião pró-labore.

Lei n. 8.629, de 25/02/93, norma vigente, que regula os dispositivos constitucionais relativos à reforma agrária, alterada pela Medida Provisória n. 2.183, de 24/08/2001 e a Lei n. 10.279 de 12/09/2001, detalhou objetivamente as exigências para o cumprimento da função 
social da propriedade do imóvel rural.

Estatuto da Cidade - Lei n. 10.257, de 30/06/2001, estabeleceu a instrumentalização para que os municípios regulamentem o cumprimento da função social do imóvel urbano.

Código Civil, de 11/01/2003 - buscando superar as amarras do Liberalismo, além de trazer à norma civil, a vinculação da propriedade à função social, vincula o exercício do direito de propriedade às finalidades econômicas e sociais, entre outras (§ $1^{\circ}$, art. 1228).

\section{FUNÇÃO SOCIAL: TENTATIVA DE CONCEITUAR}

Os vários conceitos doutrinários de função social estão vinculados à visão axiológica que cada estudioso confere ao direito de propriedade, assim podemos citar:

(...) a função social da propriedade não é senão o modo concreto de funcionar da propriedade ou, seja como exercício do direito de propriedade ou não, exigido pelo ordenamento jurídico, direta e indiretamente, por meio de imposição de obrigações, encargos, limitações, restrições, estímulos ou ameaças, para satisfação de uma necessidade social, temporal e espacialmente considerada (MORAES: 1999, p.111).

(...) função social da propriedade corresponde a um poderdever do proprietário, sancionável pela ordem jurídica. (COMPARATO apud MORAES:1999, p. 112)

A chamada 'função social da propriedade' nada mais é do que o conjunto de normas da Constituição que visa, por vezes até com medidas de grande gravidade jurídica, recolocar a propriedade na sua trilha normal. (BASTOS, Celso Ribeiro apud MORAES:1999, p.112)

Na doutrina jurídico-agrária a função social da propriedade consiste na correta utilização econômica da terra e na sua justa distribuição, de modo a atender a bem estar social da 
coletividade, mediante o aumento da produtividade e a promoção da justiça social. (ARAÚJO, Telga apud MORAES:1999, p.113).

\section{FUNDAMENTOS DA FUNÇÃO SOCIAL}

0 fundamento da função social da terra há que ser inter-relacionado com a visão do Direito de Propriedade.

Visão individualista - $\left(\mathrm{LOCKE}^{5}\right)$ Propriedade como direito natural e subjetivo. Na visão individualista de propriedade, não há falarse em função social, pois, para esta doutrina o Estado deve respeitar a propriedade individual em toda sua extensão, evitando quaisquer limitações à propriedade. Miguel Reale apud Braga, ensina que a essência deste pensamento estaria em que cada homem deve cuidar de seu interesse e de seu bem, assim, consequentemente, mediante automático equilíbrio dos interesses individuais, realizaria o bem social ou bem comum (BRAGA:1991, p. 89).

Visão socialista - $\left(\right.$ MARX $\left.^{6}\right)$ Visa erradicar a propriedade privada, pois é considerada a razão de todas as iniqüidades da classe capitalista em desfavor do proletariado, buscando uma nova ordem social. Segundo José Braga "As doutrinas coletivistas fazem girar sobre a propriedade privada toda sua crítica e, embasadas numa dinâmica materialista, consideram a propriedade individual inconciliável com o bem-estar social e a felicidade coletiva" (BRAGA:1991, p. 92).

Visão de Deguit ${ }^{7}$ - A propriedade individual deixa de ser um direito, subjetivo, para converter-se em uma função social, "a propriedade não é um direito é uma função social. O proprietário, o possuidor

\footnotetext{
${ }^{5}$ John Locke (1632-1704), filósofo do predecessor Iluminismo. Ele advogava que todos os homens são iguais e que a cada deverá ser permitido agir livremente desde que não prejudique nenhum outro. Com este fundamento, ele fez a justificação clássica da propriedade privada ao declarar que o mundo natural é a propriedade comum de todos os homens, mas que qualquer indivíduo pode apropriar-se de uma parte dele ao misturar o seu trabalho com os recursos naturais.

${ }^{6} \mathrm{Karl}$ Marx, economista, considerado um dos fundadores da Sociologia.

${ }^{7}$ León Deguit e Augusto Conte são os precursores do princípio da função social.
} 
de uma riqueza, tem pelo fato de possuir esta riqueza, uma função social a cumprir; enquanto cumpre essa missão, seus atos de propriedade estão protegidos" (MARQUESI:2001, p. 91).

Visão Tomista - A Igreja Católica com as Encíclicas Papais (Rerum Novarum, Leão XIII, 1891; Quadragésimo Ano, Pio XI, 1931; Mater et Magistra $^{8}$, João XXIII, 1961) passou exercer importante papel na humanização nas relações agrárias, vindo redimir-se das práticas absolutistas do período medieval. É a teoria que propugna pela defesa do condicionamento do direito de propriedade ao seu bom uso, hoje adotada no Brasil, e na maioria dos países ocidentais, garantindo o direito de propriedade vinculado ao cumprimento de sua função social, ou seja, a propriedade tem uma função social.

\section{FUNÇÃO SOCIAL: LEITURA SISTEMÁTICA DO ORDENA- MENTO JURÍDICO}

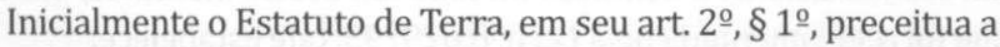
função social, in verbis:

Art. $2^{\circ}$ - É assegurada a todos a oportunidade de acesso propriedade da terra, condicionada pela sua função social, na forma prevista nesta lei.

$\S 1^{\mathrm{o}}$ - A p ropriedade da terra desempenha integramente a sua função social quando, simultaneamente:

a) favorece o bem-estar dos proprietários e dos trabalhadores que nela labutam, assim como de suas famílias;

b) mantém níveis satisfatórios de produtividade;

c) assegura a conservação dos recursos naturais;

d) observa as disposições legais que regulam as justas relações de trabalho entre as que a possuem e a cultivam.

Posteriormente a Constituição Federal de 1988, reproduziu os

\footnotetext{
${ }^{8}$ É uma Carta Encíclica do Papa João XXIII, de 15 de maio de 1961, Sobre a recente evolução da Questão Social à luz da Doutrina Cristã, no septuagésimo aniversário da Encíclica Rerum Novarum e no terceiro ano de seu pontificado.
} 
requisitos, que estão elencados no art. 186 e devem ser atendidos concomitantemente:

Art. 186 - A função social é cumprida quando a propriedade rural atende, simultaneamente, segundo critérios e graus de exigências estabelecidas em lei, aos seguintes requisitos:

I - aproveitamento racional e adequado;

II - utilização adequada dos recursos naturais disponíveis e preservação do meio ambiente;

III - observância das disposições que regulam as relações trabalho;

IV - exploração que favoreça o bem-estar dos proprietários e trabalhadores.

Destaque-se que o art. 185 da Lei Maior exclui da suscetibilidade de desapropriação para fins de reforma agrária, os imóveis produtivos e a pequena e média propriedade. Assim, restou à legislação infraconstitucional a definição de cada um destes institutos, matéria que foi regulamentada pela Lei n. 8.629/93, que estabelece:

Art. 6을 Considera-se propriedade produtiva aquela que, explorada econômica e racionalmente, atinge, simultaneamente, graus de utilização da terra e de eficiência na exploração, segundo índices fixados pelo órgão federal competente.

§1‥ 0 grau de utilização da terra, para efeito do caput deste artigo, deverá ser igual ou superior a $80 \%$ (oitenta por cento), calculado pela relação percentual entre a área efetivamente utilizada e a área aproveitável total do imóvel.

§ 2. 0 grau de eficiência na exploração da terra deverá ser igual ou superior a $100 \%$ (cem por cento), e será obtido de acordo com a seguinte sistemática:

I - para os produtos vegetais, divide-se a quantidade colhida de cada produto pelos respectivos índices de rendimento estabelecidos pelo órgão competente do Poder Executivo, para cada Microrregião Homogênea; 
II - para a exploração pecuária, divide-se o número total de Unidades Animais (UA) do rebanho, pelo índice de lotação estabelecido pelo órgão competente do Poder Executivo, para cada Microrregião Homogênea;

III - a soma dos resultados obtidos na forma dos incisos I e II deste artigo, dividida pela área efetivamente utilizada e multiplicada por 100 (cem), determina o grau de eficiência na exploração.

$\S 3 \%$. Considera-se efetivamente utilizadas:

I - as áreas plantadas com produtos vegetais;

II - as áreas de pastagens nativas e plantadas, observado o índice de lotação por zona de pecuária, fixado pelo Poder Executivo;

III - as áreas de exploração extrativa vegetal ou florestal, observados os índices de rendimento estabelecidos pelo órgão competente do Poder Executivo, para cada Microrregião Homogênea, e a legislação ambiental;

IV - as áreas de exploração de florestas nativas, de acordo com plano de exploração e nas condições estabelecidas pelo órgão federal competente;

V - as áreas sob processos técnicos de formação ou recuperação de pastagens ou de culturas

$\S 4 \%$. No caso de consórcio ou intercalação de culturas, considera-se efetivamente utilizada a área total do consórcio ou intercalação.

$\S 5$ ․ No caso de mais de um cultivo no ano, com um ou mais produtos, no mesmo espaço, considera-se efetivamente utilizada a maior área usada no ano considerado.

$\S 6$. Para os produtos que não tenham índices de rendimentos fixados, adotar-se-á a área utilizada com esses produtos, com resultado do cálculo previsto no inciso I do $§ 2^{\circ}$ deste artigo.

$\S 7$. Não perderá a qualificação de propriedade produtiva o imóvel que, por razões de força maior, caso fortuito ou de renovação de pastagens tecnicamente conduzida, devidamente comprovados pelo órgão competente, deixar de apresentar, no ano respectivo, os graus de eficiência na exploração, 
exigidos para a espécie.

$\S 8^{\circ}$. São garantidos os incentivos fiscais referentes ao Imposto Territorial Rural relacionados com os graus de utilização e de eficiência na exploração, conforme o disposto no art. 49 da Lei n. 4.504, de 30 de novembro de 1964.

Fator Econômico - o aproveitamento racional e adequado tem em conta a forma de exploração e o coeficiente de produtividade, que o art. $6^{\circ}$ da Lei n. 8.629/93 se encarregou de detalhar como sendo Grau de Utilização (GUT) de, no mínimo $80 \%$ (oitenta por cento) e Grau de Eficiência na Exploração (GEE) de, no mínimo, 100\% (cem por cento), de forma que a exigência é a mesma para a conceituação do que é propriedade produtiva.

Destaque-se que o art. 185 da Constituição da República Federativa do Brasil, veda a desapropriação, para fins de reforma agrária, a pequena e média propriedade, desde que seu proprietário não possua outra e a propriedade produtiva. Destarte, mesmo que não sejam cumpridos todos os requisitos da função social, não há falar-se em desapropriação para fins de reforma agrária. E, de acordo com o art. $6^{\circ}$ da Lei n. 8.629/93, para o enquadramento como propriedade produtiva, são exigidos apenas os requisitos econômicos, atendidos estes, não há previsão legal para a desapropriação nos moldes aventados. Prevalece a idéia capitalista de que há o predomínio do interesse econômico.

Da redação acima transliteralizada abstrai-se que a lei ordinária prestigiou a produtividade somente em sua vertente econômica sem contudo mencionar o atendimento de proteção ambiental e das relações sociais no campo. 0 texto constitucional ressalta a obrigatoriedade de atendimento concomitante das três exigências, logo numa interpretação sistematizada, a Lei n. 8.629/93 somente poderia ser considerada constitucional, se trouxesse para o seu texto, as determinações da Lei Maior em sua integralidade.

Fator Ambiental - A proteção ambiental, guindada ao requisito da função social, passa a integrar o próprio conteúdo do direito de 
propriedade. A incorporação de valores ambientais, na limitação do direito de propriedade, vem na vertente da preocupação do homem com a manutenção de sua sobrevivência, buscando normatizar o uso do meio ambiente, sem, no entanto, extingui-lo.

Fator Humano - A exploração da terra deve atender ao bemestar dos que nela trabalham e dos proprietários. Os trabalhadores devem gozar de condições que lhes permitam uma existência digna, não apenas considerando as condições básicas, mas também, as comodidades que os recursos técnicos têm propiciado nos tempos atuais.

\section{FUNÇÃO SOCIAL: FUNDAMENTO PARA CONSERVAÇÃO DA VITALIDADE E DIVERSIDADE DO PLANETA}

A terra é uma manancial de riquezas e bem de produção por excelência, é parte do meio ambiente onde vive o ser humano, no entanto é um bem finito e sua conservação e manuseio exigem racionalidade e prudência. A sua manutenção é ponto primordial para a sobrevivência da humanidade no planeta. Entretanto, o constante desenvolvimento e as necessidades do ser humano não permitem que seja considerado um templo intocável, deve-se utilizá-la com bom senso. Há bem pouco tempo, incentiva-se o uso da propriedade de maneira irresponsável, não se importando com os custos ambientais que as várias atividades pudessem desencadear, a única preocupação era o desenvolvimento econômico.

Atualmente, após várias tragédias ecológicas (efeito estufa, chuva ácida, etc.), algumas questões sócio-políticos (descontrole do consumo, do crescimento econômico, etc.), e depois de vários fóruns sobre meio ambiente, está ocorrendo uma forçosa conscientização coletiva para garantir o bem-estar geral, compatibilizando crescimento econômico e proteção do meio ambie nte, através de um desenvolvimento sustentável, com planejamento não só das necessidades e aspirações das populações, mas com integração das questões ambien- 
tais, sociais e econômicas, é a chamada visão pluralista, trazida pela Agenda 219.

É nesse contexto que o desenvolvimento sustentável deve ser integrado à função social da propriedade para se ter a garantia de um habitat saudável ao homem, pois a não observância de tal princípio produzirá reflexos negativos não só na ordem econômica, mas em todos os setores.

A função social da terra não deve se ater somente à distribuição da terra a quem a faça produtiva, mas essencialmente a produza de forma racional e adequadamente, utilizando apropriadamente os recursos naturais disponíveis e preservando o meio ambiente, numa revisão da ordem econômica, social e política até então em vigor, moldada ainda nos ideais da Revolução Francesa. Deve-se formular um novo paradigma de valores.

As políticas governamentais, de reforma agrária, não devem se pautar somente na distribuição de terra, mas principalmente na preservação dos recursos renováveis, na diversidade biológica, em suma na ação do homem na natureza, pois isso é essencial para a sobrevivência da humanidade. Em pleno século 21 não se pode ter uma visão sustentada somente no poder econômico.

\section{CONCLUSÃo}

A Revolução Francesa com seu ideário de liberdade, igualdade e fraternidade teve como principal sustentáculo o poder econômico da burguesia. A transferência de poder político dos nobres aos burgueses, ocorreu sem alterar a organização hegemônica social, permanecendo a dicotomia de dominantes e dominados. Não foi uma revolução das bases sociais e sim, do poderio de dominação.

\footnotetext{
${ }^{9}$ Compromisso assumido pelos países participantes da CNUMAD-Conferência das Nações Unidas sobre Meio Ambiente e Desenvolvimento, realizada na cidade do Rio de Janeiro, em 1992, também conhecida como Eco-92.
} 
A burguesia alçada à condição de detentora da política e da economia buscou extirpar qualquer reminiscência de repartição de domínio e enrijece o sistema legal de detenção da propriedade, convalidando uma ordem jurídica mais inflexível do que a do Império Romano.

A idéia de propriedade absoluta e a plena garantia estatal tornaram-se insustentável e aos poucos foi abrindo ensanchas ao pensamento coletivista principalmente com a mudança de postura da Igreja Católica, no século XIX, que adotou a visão Tomista de que a propriedade tem uma função social.

Atualmente, no Brasil vige a ordem econômica da propriedade, em detrimento de qualquer outro interesse. Os prismas do ambiente e do trabalhador rural permanecem ainda em segunda categoria.

A conseqüência desta política tem sido um cenário de grande devastação e de expulsão do rurícola do campo para as zonas urbanas, engrossando os cordões da pobreza e violência, em decorrência da ausência de estruturas de empregos, habitação, saúde, educação etc. Revelando um sistema ineficaz e segregador.

0 cumprimento da função social da terra somente será pleno quando houver visão da terra como ente íntegro e não fragmentado e quando o maior número de pessoas tiver acesso a ela para viver e trabalhar, produzindo alimentos para uma parcela considerável da população mundial, mas essencialmente conservando os recursos naturais e observando o bem estar de todos, garantindo um desenvolvimento sustentável no campo, ressaltando a importância de uma reforma agrária que valorize as pessoas e não uma reforma de mercado, promovida por instituições internacionais que se preocupam somente com o lucro.

A terra não se destina a amealhar riquezas concentradas e sim, a propiciar a sobrevivência do ser humano em condições dignas, daí a fundamental importância do princípio da função social da terra como instrumento da conservação da vitalidade e diversidade do planeta. 


\section{REFERÊNCIAS BIBLIOGRÁFICAS}

SILVA, José Afonso da. Comentário Contextual à Constituição. São Paulo: Ed. Malheiros. 3aㅡ edição. 2007. p.743-751.

BORGES, Paulo Tormin. Institutos básicos de direito agrário. São Paulo: Ed. Juriscredi. 1974.

BRAGA, José. Introdução ao direito agrário. Belém: CEJUP/ Fundação Lourenço Braga. 1991.

CAMARGOS, Luciano Dias Bicalho. 0 Imposto territorial rural e a função social da propriedade: doutrina, a prática e jurisprudência. Belo Horizonte: Del Rey. 2001.

FACHIN, Luiz Edson. A função social da posse e a propriedade contemporânea (uma perspectiva da usucapião imobiliária rural). Porto Alegre: Fabris. 1988.

GUIMARÃES, Rejane Silva. A função social ambiental. Anais do I Seminário Estadual de Direito Agrário - SEDAG (2001: Goiânia). Anais. Goiânia: UFG, 2001.

HEINEN, Milton I. Institutos de direito agrário. cap. II. Apostila das aulas da disciplina Direito Agrário na UCG, Goiânia. 2001.

MARQUES, Benedito Ferreira. Direito agrário brasileiro. Goiânia: AB. 1996.

MARQUESI, Roberto Wagner. Direitos reais agrários. Curitiba:Juruá. 2001.

MIRANDA, Alcir Gursen de. Teoria do direito agrário. Belém: CEJUP. 1989.

MORAES, José Diniz de. A função social da propriedade e a Constituição Federal de 1988. São Paulo:Malheiros. 1999.

OPTIZ, Oswaldo e OPITZ, Silvia. Tratado de direito agrário brasileiro. São Paulo: Saraiva. 1983. 
PAULA, Gil César Costa de. Terra e propriedade rural: caracterização de sua função social. Revista Goiana de Direito Agrário, Goiânia. n. 1 , a. 1, 1997, p. 85/113.

VIAL, Sandra Regina Martini. Propriedade da terra: análise sociojurídica. Porto Alegre: Livraria do Advogado. 2003.

\section{SÍTIOS CONSULTADOS}

http://pt.wikipedia.org/

http://www.incra.gov.br/

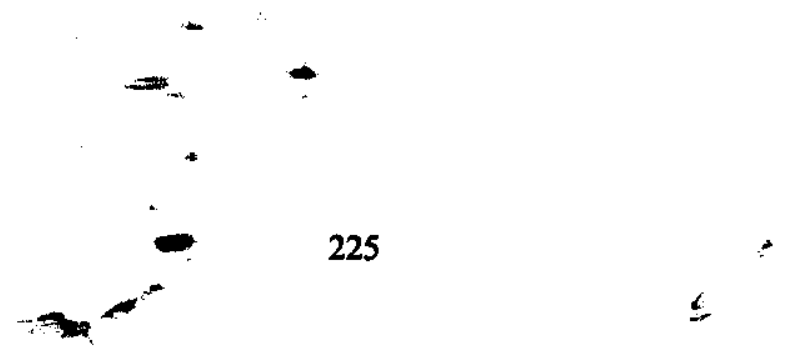

